\title{
Weakness in the mechanical properties of the femur of growing female rats exposed to cadmium
}

\author{
Małgorzata M. Brzóska • Katarzyna Majewska •
} Janina Moniuszko-Jakoniuk

Published online: 6 December 2006

(C) Springer-Verlag 2006

Erratum to: Arch Toxicol 79:277-288

DOI 10.1007/s00204-005-0650-z

and

Arch Toxicol 79:519-530

DOI 10.1007/s00204-005-0659-3

Unfortunately the article by M.M. Brzóska et al. "Weakness in the mechanical properties of the femur of growing female rats exposed to cadmium" has been printed twice. The valid final version of the article is that published in the September 2005 issue of Archives of Toxicology (2005) 79:519-530.

The online version of the original article can be found at http:// dx.doi.org/10.1007/s00204-005-0650-z and http://dx.doi.org/ 10.1007/s00204-005-0659-3.

M. M. Brzóska $(\bowtie) \cdot$ J. Moniuszko-Jakoniuk Department of Toxicology,

Medical University of Białystok,

Mickiewicza 2c, 15-222 Białystok, Poland

e-mail:mmbr@poczta.onet.pl

K. Majewska

Chair of Food Plant Chemistry and Processing,

Faculty of Food Science,

University of Warmia and Mazury in Olsztyn,

Plac Cieszyński 1, 10-957 Olsztyn, Poland 